\title{
Review on Materials Used for Enhancing the Efficiency of Solar Cells
}

\author{
Anil Dhawan $^{1, *}$ and S Faheem Naqvi ${ }^{1}$ \\ ${ }^{1}$ School of Basic and Applied Sciences, Anand International College of Engineering,Near Kanota, Agra Road, \\ Jaipur-303012, India
}

\begin{abstract}
Global resources are limited and mindless use of them will finally lead to a scarcity. The need of the hour is to find the alternative energy resources which are abundant in nature and which deviate us from using fossils fuels. Solar Energy has gained a significant popularity in the past few decades as it is clean, meaning it does not release greenhouse gases and other harmful pollutants. It is also an abundant source of energy as it is available till the existence of the planet. Unlike fossil fuels, which are finite and cannot be replenished for thousands of years. Another drawback of fossil fuels is that they emit greenhouse gases and contribute to global climate change. Solar energy is an important technology for many reasons and has become a popular topic as many scientists around the world are working to increase the photo-electron conversion efficiency with minimum production cost. Diversified approaches have been undertaken to enhance the efficiency of solar cell. This paper will review the current state of art on photovoltaic cells (PVCs) in context to the materials used for fabrication, their possible cost and their working efficiency. This paper will also undertake the challenges that came across during the whole process and their possible solutions.
\end{abstract}

Keywords: Solar cells, Materials, Generations, Semiconductors, Production, Efficiency.

\section{INTRODUCTION}

Sun light is eternal and also abundant in arid regions. This is the energy that can be collected by modern technology and can be transformed into usable energy for instance, electricity [1]. It has been reported that two minute of sun energy is sufficient toprovide the world with one year's energy needs of entire humanity; thanks to the technology we are now able to harvest sunlight for energy conservation.

Although, there is a significant development of the photovoltaic industry over the past decades, the efficiency and production cost are still a huge confrontation.

Hence, new methods have to be employed in order to step up the efficiency of photovoltaic cell with reduced cost [2, 3]. In 1839, French physicist Alexandre- Edmond Becquerel discovered the photovoltaic effect which is employed to produce electric energy directly from the radiation of the Sun. This effect can be seen in semiconducting materials. Solar cell is based on photovoltaic influence and it is more to do with the generating, trapping, recombination of electron-hole pairs throughout the semiconducting material. The potential difference is generated between the terminals by the flow of the electrons and due to the applied electric field; electrons are drifted in the

\footnotetext{
*Address correspondence to this author at the School of Basic and Applied Sciences, Anand International College of Engineering, Near Kanota, Agra Road, Jaipur-303012; Tel: +91-9829276707;

E-mail: dr.anildhawan11@gmail.com
}

direction of field generating currents. The Structure of PVCs is based on the amalgamation of n-type or $p$ type semiconductors; in both cases the material is electrically neutral though.

The basic chemistry of a solar cell is very much affected by the selection of the material during its formation. A very high level of chemical purity is needed for the material because even a trace of impurities can affect the material properties to a great extent.

First generation (1GEN) solar cell devices are focused on thick monocrystalline and polycrystalline films, mainly silicon (Si) and on GaAs. The biggest disadvantage of the first-generation solar cell is that they suffer from high fabrication and installation costs. The second generation (2GEN) solar cells aimed at reduced cost and are based on thin film technologies. The object of $2 \mathrm{GEN}$ is to use cheap quality material to reduce the production cost for instance a-Si, CdTe etc [4-6]. Although, the 2GEN solar cells have seen drastic reduction in the cost as the quantity of material needed is less. Its efficiency has reduced significantly. Now the idea is to discover a technology that decreases the cost and increases the efficiency. Therefore, the focus is basically on the technologies that maximize electron avalanche and improves the energy capturing processes within the sun spectrum [710].

With this regard the third generation (3GEN) technologies are considered to provide cheap and high 
efficiency solar cells. The 3GEN solar cells use nontoxic material that is abundant in nature and are suitable for stepping up the production. Moreover, 3GEN solar cells use new range of materials such as nanostructured and organic to achieve high conversion efficiencies [11-13].

Nanotechnology promises significant improvements in the manufacturing cost and photo-electron conversion efficiency of photovoltaic cells. At the microscopic level, the structure of solar cell is an extended network of electron routes. These routes are altered to optimize charge collection and more attention is made on the improvement in the energy capture within the solar spectrum.

Tinted areas:

$67-87 \%$ representing thermodynamic limit

$31-41 \%$ representing single bandgap limit

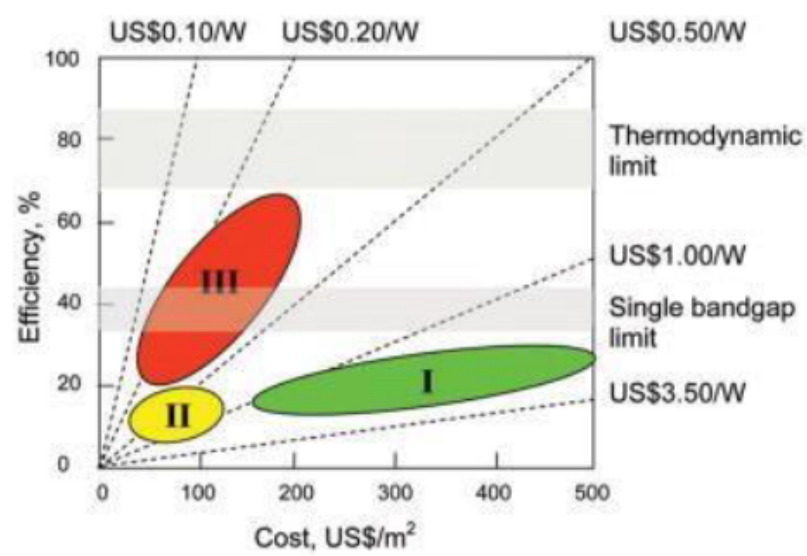

Figure 1: Efficiency and production cost of first (I), second (II) and third (III)generation solar cell technologies-courtesy [14].

The 3GEN solar cells employed several important technologies with a view to absorb all incident solar spectra and convert them to electricity. Improving the architecture of regular crystalline material by using nano-crystalline materials can increase the absorbance of all incident solar spectra in thin films or multilayered solar cells. This enhancement requires an electrolyte to pass the charge to the electrodes from the photoacceptor in dye sensitized or polymer based solar cells [15].

However, in nanoparticle-based solar cells, the atomic distance should be small enough to transfer the charge directly. In order to acquire a durable and costeffective photovoltaic cell, it is essential to have a correct combination of photo-acceptor, charge transfer structures, and proper electrodes within the photovoltaic cell [16].
The efforts should be made to develop an amalgamated structure that is not complicated and is easily upgraded for commercial and domestic uses without any compromise on the cost. Thus, this paper aims at comprehending the role of materials in solar cell manufacturing and their potential impacts in cost and efficiency.

\section{ROLE OF MATERIALS}

In view of the problem associated with the first- and second-generation silicon and oxides semiconductor solar cell in terms of their efficiency, cost and corrosion of electrodes, the possible solutions come in the form of third generation solar cells comprising mainly of Dye sensitized solar cells (DSSC). DSSC technology separates the two main functions in conventional solar cell that uses a donor and acceptor type materials to form a hetero junction in favoring the separation of exciton into two carriers. whereas the charge generation in DSSC is conducted at semiconductor-dye interface and the phenomenon of charge transport is carried by semiconductor and the electrolyte. A DSSC contains a light harvesting layer on a photoelectrode and a platinum coated layer on counter electrode; both electrodes are made of transparent conducting oxide (TCO) substrate, an iodine-based electrolyte fills the space between the electrodes to serve as a redox mediator in a sandwich type structure. The efficiency of DSSC depends on the electron transfer rates, which in turns depend on crystallinity, morphology and surface area of the semiconductor. However, DSSC based on nano-crystalline material such as $\mathrm{TiO}_{2}$ has better efficiency.

As per the literature the most successful DSSCs are based on $\mathrm{TiO}_{2}$ nanoparticles owing to their interconnected pore networks high porosity and large surface area, which allows sufficient dye- absorption and efficient light harvesting [17-19]. In order to further increase the solar cell efficiency, $\mathrm{TiO}_{2}$ films are coated with oxides of $\mathrm{Zr}$ nano-particles, which creates a larger surface area than the single $\mathrm{TiO}_{2}$ film [20]. $\mathrm{Zr}$ has low toxicity compared to other metals as well as efficient electron transfer moreover $\mathrm{Zr}$ doping expands the surface area by decreasing the $\mathrm{TiO}_{2}$ particle size and enhances the open circuit voltage by improving electron transfer through energy modification of conduction band. Thus, $\mathrm{Zr}$ is used as a doping element to increase $\mathrm{TiO}_{2}$ performance. These oxides increase the amount of dye loading, short-circuit photocurrent density and solar conversion efficiency. 
Dye-sensitized solar cells [DSSCs] have generated a considerable research interest because of their high energy conversion efficiency (approx. 11\%) and low production costs [21]. O Regean and Gratezal in 1991 initiates for the first time the development of DSSCs. With the development of DSSC the conventional solid state photovoltaic technologies are now challenged by devices functioning at a molecular and nano level. DSSC perform relatively better as compared with other solar cell technologies under diffuse light conditions and at higher temperatures. DSSC offers the possibilities to design solar cells with a large flexibility in shape, colour and transparency. Xuxu Liu et al. [22] have worked on different dyes containing phenothiazine and found that these dyes enhance the electron injection efficiency and reduces the dye aggregation.

The stability and efficiency of dye sensitized solar cells based on papaya-leaf dye has been studied by Suyitno Suyitno et al. [23] and they have reported that the natural dye based DSSC has increased the performance and stability. Md. Ashraf Hossain et al. [16] have investigated $\mathrm{TiO}_{2}$ nanotube/nanoparticles to improve the power conversion efficiency of DSSC. Zhan' ao Tan et al. [24] have worked on polymers solar cells with as prepared Zircoinium acetylacetonate film as cathode buffer layer for fabricating large area flexible PSCs. The development of organic dyes for DSSC has been investigated by Lars Kloo [25]. Puhong Wen et al. [26] have investigated the dye absorption parameter for the DSSC. The investigation of nano structured photo electrodes for the DSSC has been studied by Qifeng Zhang et al. [27]. In 2008 the role of $\mathrm{TiO}_{2}$ compact layer in DSSC incorporating planar organic dyes has been studied by Anthony Burk et al. [28]. In view of above-mentioned studies performed on DSSC by researchers there is wide scope in this field for investigating the suitable materials and dyes to enhance the performance and efficiency of DSSCs.

Recently, perceptible progress has been made in improving the overall working efficiency of solar cell structures by incorporating the quantum dots (QDs). QD's are nanostructure semiconducting materials that belongs to II-VI, III-V and IV-VI groupsin periodic table. Since the movement of the electrons and holes are restricted to the three directions of the space, these materials have a discrete spectrum of quantized energy. In the QD nanostructures, the radius of the particle is comparable with exciton bohr radius of the material. Coupled with this, quantum dots consist of 100 to 100,000 number of atoms per particle [30]. Therefore, the removal or addition of a few numbers of atoms or molecules of a quantum dot can make wonders in the photo physical properties of the material [31]. The stability and absorption rate of quantum dots are higher than the high-performance dye molecules. In usual semiconductors electrons sprint to the conduction band when energy higher than the band gap energy is provided. However, in quantum dots, due to quantum confinement effect, the two bands are too close that they are considered as continuous bands [32]. Hence, the values of these bands are quantized, in a way that an improvement of QDs' size implies a

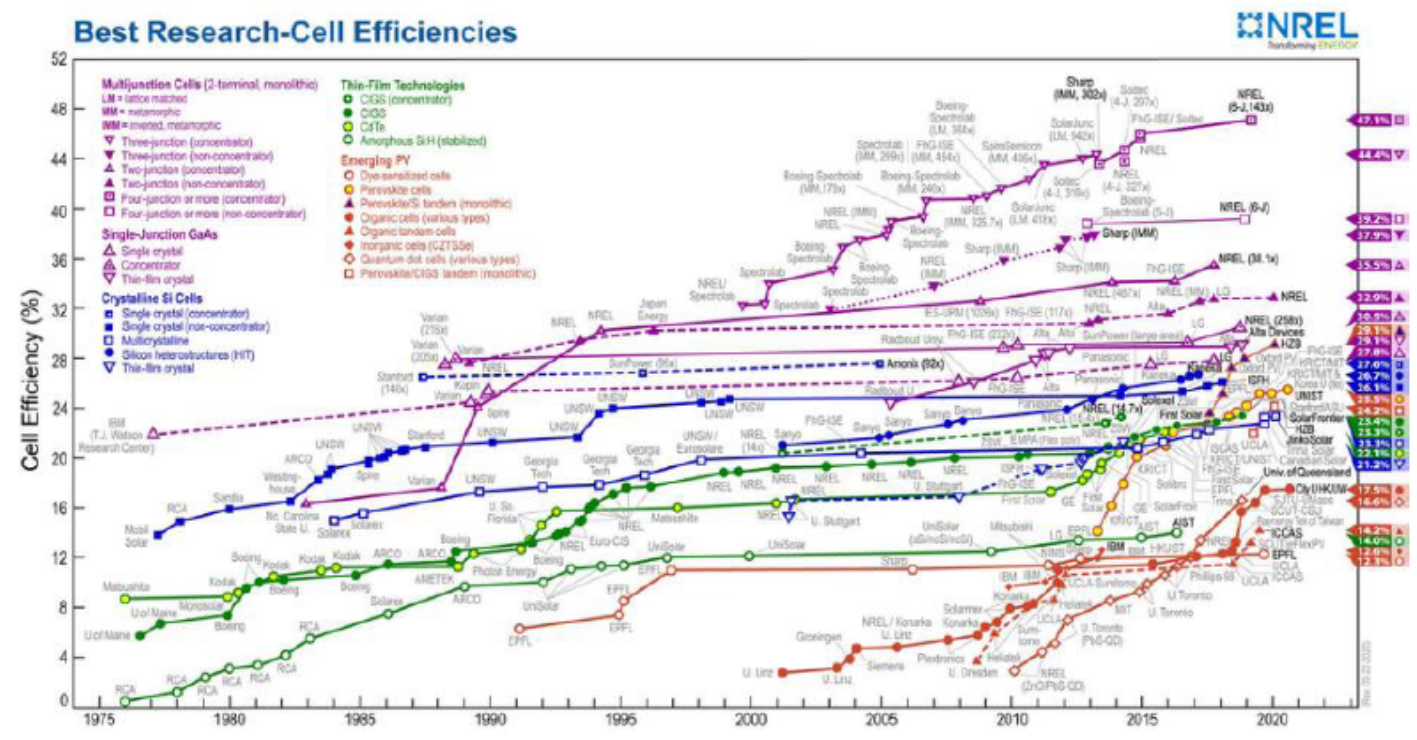

Figure 2: Solar Cell Energy Conversion Efficiency Time line -courtesy [29]. 


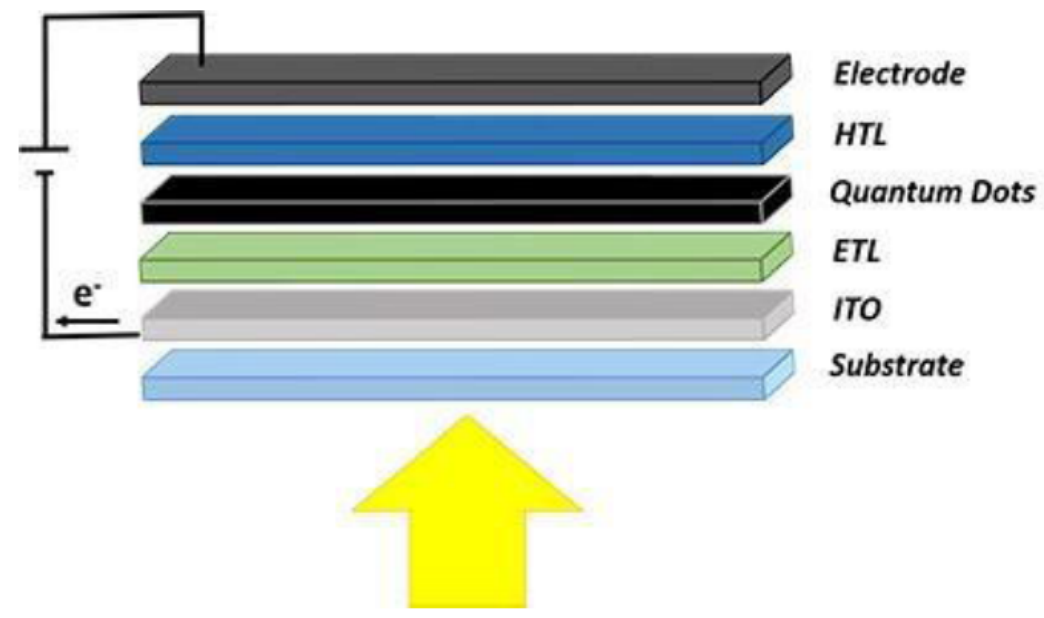

Figure 3: Sketch of a quantum dot based LED structure -courtesy [35].

change in the band gap value and in the absorption spectrum. T. K. Nideepet al. [33] have investigated the influence of $\mathrm{ZnS}$ buffer layer on the size dependent efficiency of CdTe quantum dot sensitized solar cell. $\mathrm{He}$ found that the efficiency depends upon the size of QDs and also upon the concentration of trap states present in the quantum dots. He also concluded that ZnS coating is an effective method in enhancing the efficiency. Meibo Xing et al. [34] investigated the dependence of photovoltaic performance of $\mathrm{TiO} 2 / \mathrm{PbS}$ hetrojunction quantum dot solar cells on temperature. $\mathrm{He}$ found that temperature has great influence on the $\mathrm{J}$ $\mathrm{V}$ (current density and photovoltage) character of the solar cell, especially at the higher temperature. The results depict that open circuit photovoltage (Voc), short circuit current density (Jsc) and fill factor (FF) (the maximum power divided by the product of Jsc and Voc) are all increased when temperature decreases. Hence, there is a large increase in device performance as the quantum dot solar cell is cooled.

Many studies show that QDs-based PVCs can be used in complete buildings including windows and not just rooftops. However, this technology is still at the laboratory scale and need to be extended and verified for industrial use. The most concerning issues faced by QDs are technological immaturity and the lack of experience in the development and manufacturing process. Moreover, QDs (i.e. CdSe) are highly toxic in nature and require a very stable polymer structure [36]. Coupled with this, degradation of structure increases under aqueous and UV conditions and it becomes difficult to control particle size.

The investigation has also been done on organic solar cells or organic photovoltaic cells (OPVs) and perovskite solar cells. OPVs are the ones that involve conductive organic polymers or small organic molecules [37] for transportation of charges and absorption of light absorption to generate electricity from sunlight by the photovoltaic effect. Most organic photovoltaic cells are polymer solar cells.

Organic solar cells are solution-processable, cheap and light materials. They possess tunable electronic properties, low temperature manufacture. Hence, resulting in low production cost to fabricate a large volume [38]. They have high optical absorption coefficient therefore; they absorb large amount of light with small amount of material.

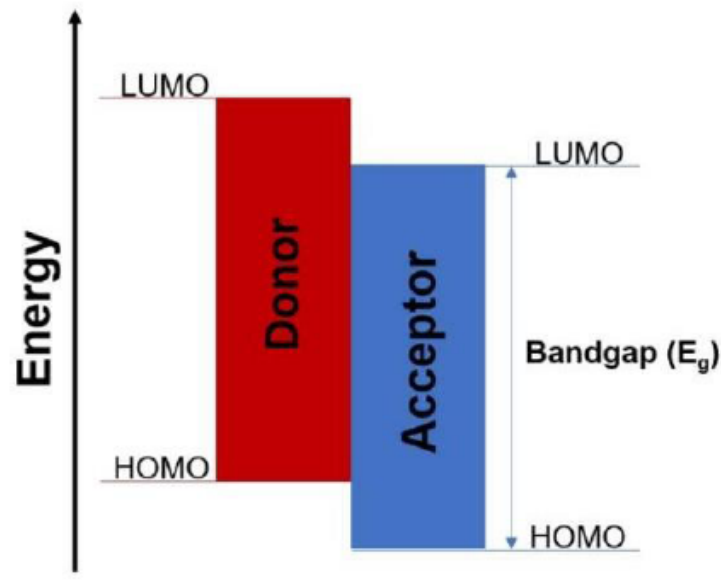

Figure 4: Energy Levels in Organic Solar cells.

Organic cells consist of donor and acceptor materials. Photons are absorbed by the donor from sun radiation where excitons are produced and confined [39]. An exciton is a bound state of an electron and an electron hole which is attracted to each 
other by the electrostatic forces and can be separated by an internal electric field of the solar cell. At the interface with the acceptor, the exciton will dissociate. The electron will be donated to the acceptor material, which has a deeper 'highest occupied molecular orbital' (HOMO) and lowest unoccupied molecular orbital (LUMO) level, at the same time the hole remains on the donor material.

From the donor material hole move to the electrode with a high work function and from the acceptor layer electrons move to the electrode with a low work function. The distance traveled by the exciton during its lifetime is referred as the diffusion length ID. Diffusion length in organic semiconductors is limited by a distance of approx. $10 \mathrm{~nm}$ due to their short lifetime and low mobility [40]. The photons near the heterojunction plane that are absorbed by the characteristic length ID contribute to the photocurrent. The excitons that appear at distances equivalent to ID can effectively move toward the interface, ensuring the generation of charge carriers. In practice, in the organic solar cell with a binary structure, only a small part, about 0.01 absorbed photons, can contribute to the photo-current.

A wide range of polymers have been used for making solar cells [41-43] with alternating carboncarbon double bonds being common to all. As of 2015, polymer solar cells were able to achieve over $10 \%$ efficiency via a tandem structure [44]. In 2018, a record-breaking efficiency for organic photovoltaics of $17.3 \%$ was reached viatandem structure [45].

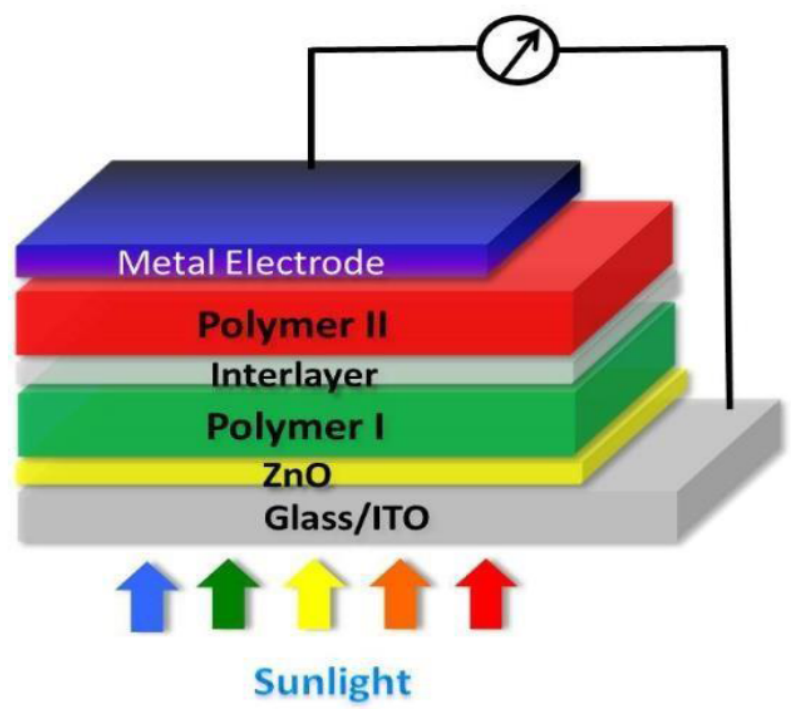

Figure 5: Tandem Polymer solar cells (which sets record for energy-conversion) - courtesy-[Wileen Wong Kromhout, University of California - Los Angeles].
Although, organic solar cells exhibit important advantages when compared to previous generations including flexibility, lightweight, lower processing cost, and less impact on surroundings [46, 47]. Its major drawbacks are low efficiency and experience substantial photochemical degradation [48].

Wide-bandgap ( 1.7-1.9 eV) perovskites are desirable for use as top sub-cells in tandem devices. Perovksite solar cells are the ones that are the hybrid organic- inorganic lead or tin halide-based material. These materials are employed as the light- harvesting active layer, which is placed between electron transport layer and hole transport layer. In perovksite solar cells, the charges separate either by injection of the electrons photo-generated in the electron transport layer or by injecting the holesin hole transport layer. In Addition, the free electrons produced near the perovksite and hole transport layer interface should diffuse through the full layer thickness before being extracted at the electron transport layer and perovksite interface, which increases the possibilities of recombination $[49,50]$. Recent studies shows that solar cells based on perovksitre materials have improved their efficiency from initial value of $3.8 \%$ in 2009 to $22.13 \%$ in 2018 in single- junction architectures [50]. It has been reported that solid state perovksite cells provide higher efficiency as compared to the liquid electrolytes [51] therefore it is suggested that solid electrolytes should be used. Current research focuses on the tandem concept that is not only attractive for obtaining ultra-high efficiency as with all other tandem cell configurations, it also can significantly reduce the fabrication cost of tandem solar cells because both sub-cells can be fabricated with solution processes. Another fascinating area in this field is employing the application of functionalized graphene as an active layer material for polymer solar cells [52-55]. Ding, $Z$. et al. [56] have studied functionalized graphene quantum dots as a novel cathode interlayer of polymer solar cells and have conclude that using an active layer of PCDTBT:PC $71 B M$, a power conversion efficiency (PCE) of $7.01 \%$ is achieved with GQDs-TMA as the $\mathrm{CIL}$, much higher than that $(<6.5 \%)$ with $\mathrm{Ca}$, LiF, or $\mathrm{ZnO}$ as the CIL. PSCs with a conventional configuration using GQDs-TMA as the CIL and PTB7$\mathrm{Th}: \mathrm{PC}_{71} \mathrm{BM}$ as the active layer show a PCE of $8.80 \%$, which they claim is the highest reported so far for PSCs containing graphene materials.

\section{CONCLUSION}

The foreseeable environmental gains, improved human well-being and welfare from employing solar 
energy have generated interest in $\mathrm{PV}$ research for past many years. The working process of PVC has been improved by the introduction of new materials such as organic and inorganic dyes, QDs, perovskite, graphene and many others. However, the availability of sufficient quantities of raw materials, inexpensive fabrication and installation, as well as easy process control to achieve a large-area product within acceptable performance tolerances with high sustainability are still the main solar cell confrontation. Therefore, to achieve the desired objectives of photovoltaics, the efficiency of solar cells should be improved without any compromise on the processing cost of PV devices. To be explicit, materials play a pivotal role in achieving the targets and if research continues while costs are kept low, investigations on new and promising materials may yield exciting prospects for expansion of solar PV.

\section{ACKNOWLEDGEMENT}

We are thankful to the Anand International College of Engineering, Jaipur for providing the support in extending the research work and motivating us for submitting the research papers for publications.

\section{REFERENCES}

[1] Manish S, Pillai IR, \& Banerjee R, Energy Sustain Dev. 10 (2006) 25-36. https://doi.org/10.1016/S0973-0826(08)60553-0

[2] Bagnall DM \& Boreland M, Energy Policy 36 (2008) 43904396. https://doi.org/10.1016/j.enpol.2008.09.070

[3] Kamat PV, The Journal of Physical Chemistry C 112 (2008) 18737-18753. https://doi.org/10.1021/jp806791s

[4] Mah O. Fundamentals of photovoltaic materials (NSPRI, National S olar Power Research Institute, Inc.) 1998.

[5] Razykov T M, Kuchkarov K M, Ergashev B A \& Esanov S A, Applied Solar Energy, 56 (2020) 94-98. https://doi.org/10.3103/S0003701X20020097

[6] Baines T, Zoppi G, Bowen L, Shalvey T, Mariotti S, Durose K \& Major J D, Solar Energy Materials and Solar Cells, 180 (2018) 196-204.

https://doi.org/10.1016/j.solmat.2018.03.010

[7] Boer KM, Journal of Photochemistry, 10 (1979) 77-110. https://doi.org/10.1016/0047-2670(79)80038-6

[8] Serrano E, Rus G \& Garci'a-Martı'nez J, Renewable and Sustainable Energy Reviews13 (2009) 2373-2384. https://doi.org/10.1016/j.rser.2009.06.003

[9] Shevaleevskiy O, Pure and Applied Chemistry, 80 (2008) 2079-2089.

https://doi.org/10.1351/pac200880102079

[10] Green MA, Third Generation Photovoltaic (Springer, Berlin) 2006.

[11] Conibeer G, Materials today, 10 (2007) 42-50. https://doi.org/10.1016/S1369-7021(07)70278-X

[12] Antonio J, Sánchez L, Díez-Pascual, AM \& Capilla RP, International Jounal of Molecular Science, 20, (2019) 976. https://doi.org/10.3390/ijms20040976
[13] Danjumma S G, Aliyu S, Suleiman S, Buhari M \& Ibrahim A, Journal of Multidisciplinary Engineering Science and Technology, 6 (2019) 10303-10319.

[14] Conibee G, Material Today 2007,10, 42-50 https://doi.org/10.1016/S1369-7021(07)70278-X

[15] Sharma K. Sharma V \& Sharma SS, Nanoscale Research Letters, 13 (2018) 1-46. https://doi.org/10.1186/s11671-018-2760-6

[16] Wibowo A, Marsudi MA, Amal MI, Ananda MB, Stephanie R, Ardy $\mathrm{H}$ \& Diguna LJ, The Royal Society of Chemistry Advances, 10 (2020) 42838-42859. https://doi.org/10.1039/D0RA07689A

[17] Hossain MD, Park J, Ahn JY, Park C, Kim YA, SHK \& Lee D, Electrochimica Acta, 173 (2015) 665-671. https://doi.org/10.1016/j.electacta.2015.05.141

[18] Park K, Zhang Q, Xi J \& Cao G, Thin Films 588 (2015) 19-25. https://doi.org/10.1016/j.tsf.2015.04.054

[19] Kim B S, Park J Y, Kim C S, Kim S B, Song D K, Jang H D, Lee S E \& Kim T, Electrochemica Acta, 174 (2015) 502-507. https://doi.org/10.1016/j.electacta.2015.06.022

[20] Wang J, Jin EM, Park JY, Wang WL, Zhao XG \& Gu HB Nanoscale Research Letters 7 (2012) 98. https://doi.org/10.1186/1556-276X-7-98

[21] Chergui Y, Nehaouha N \& Mekki DE, Intech Open, (2011) 49-64.

[22] Liu X, Long J, Wang G, Pei Y, Zhao B \& Tan S, Dyes and Pigments, 121 (2015) 118-127. https://doi.org/10.1016/j.dyepig.2015.05.012

[23] Suyitno S, Saputra $T$ J, Supriyanto A \& Arifin Z, Spectrochimica Acta Part A: Molecular and Biomolecular Spectroscopy 148 (2015) 99-104. https://doi.org/10.1016/j.saa.2015.03.107

[24] Tan Z, Li S, Wang F, Qian D, Lin J, Hou J \& Li Y, Scientific Reports, (2014) 4: 4691. https://doi.org/10.1038/srep04691

[25] Kloo L, Chem. Commun, 49 (2013) 6580-6583. https://doi.org/10.1039/c3cc42733a

[26] Wen $P$, Xue $M$, Ishikawa $Y$, Itoh $H$ \& Feng $Q$, American Chemical Society 4 (2012) 1928-1934. https://doi.org/10.1021/am3001693

[27] Zhang Q, Cao G, Nano Today, 6 (2011) 91-109. https://doi.org/10.1016/j.nantod.2010.12.007

[28] Burke A, Ito S, Snaith H, Bach U, Kwiatkowski \& Gratzel M, Nano Letters, 8 (2008) 977-981. https://doi.org/10.1021/nl071588b

[29] Best research cell efficiencies (NREL http://www.nrel.gov/ncpv/, accessed 2020)

[30] Alivisators AP, Science, 271 (1996) 933-937 29. https://doi.org/10.1126/science.271.5251.933

[31] Ashoori R C, Nature, 379 (1996) 413-419. https://doi.org/10.1038/379413a0

[32] Bera D, Qian L, Tseng T K \& Holloway P H, Materials 3 (2010) 2260-2345. https://doi.org/10.3390/ma3042260

[33] Nideep TK, Ramya $M$ \& Kailasnath $M$, Superlattices and Microstructure, 130 (2019) 175-181. https://doi.org/10.1016/j.spmi.2019.04.034

[34] Xing M, Zhang $Y$, Shen Q \& Wang R, Solar Energy, 195 (2020) 1 -5.

https://doi.org/10.1016/j.solener.2019.11.010

[35] Lutfullin $M$, Sinatra L \& $M$. Bakr $O$, Quantum Dots for Electronics and Energy Applications-Marat (King Abdullah University of Science and Technology, Thuwal, Saudi Arabia)

[36] Brunetti V, Chibli H, Fiammengo R, Galeone A, Malvindi M A, Vecchio G, Cingolani R, Nadeau J L \& Pompa P P, Nanoscale 5 (2013) 307-317. 


\section{https://doi.org/10.1039/C2NR33024E}

[37] Pulfrey LD, Photovoltaic Power Generation (Van Nostrand Reinhold Company, New York) 1978.

[38] Nelson \& Jenny, Materials Today, 14 (2011) 462-47. https://doi.org/10.1016/S1369-7021(11)70210-3

[39] Díez-Pascual AM, Luceño JA, Sanchez, Capilla RP, Díaz PG, Polymers, 10 (2018) 217. https://doi.org/10.3390/polym10020217

[40] Dennler G, Lungenschmied C, Neugebauer H, Sariciftci N S \& Labouret A, Journal of Materials Research, 20 (2005) 3224-3233. https://doi.org/10.1557/jmr.2005.0399

[41] Jørgensen $M$, Carlé JE, Søndergaard RR, Lauritzen $M$, Dagnæs, Hansen N A, Byskov S L, Andersen T R, LarsenOlsen T T, Böttiger A P L \& Andreasen B.I. Solar Energy Material and Solar Cells 119 (2013) 84-93. https://doi.org/10.1016/j.solmat.2013.05.034

[42] Etxebarria I, Ajuria J \& Pacios R, Organic Electrons, 19 (2015) 34-60 https://doi.org/10.1016/j.orgel.2015.01.014

[43] Hemavathi B, Ahipa TN \& Pai RK, European Polymer Journal, 72 (2015) 309-340. https://doi.org/10.1016/j.eurpolymj.2015.09.017

[44] Jingbi Y, Letian D, Ken Y, Takehito K, Kenichiro O, Tom M, Keith E, Chun-Chao C, Nature Communications, 4 (2013) 1446.

[45] Yongsheng C, Yong C, Hin-Lap Y, Ding X R, Xiao L, Ke Z, Yanbo X W \& Xin Z, Science, 361 (2018) 1094-1098. https://doi.org/10.1126/science.aat2612

[46] Riccardo P, Chiara C, Andrea B, Francesca T \& Nadia C, Solar Energy Materials and Solar Cells, 100 (2012) 97-114. https://doi.org/10.1016/j.solmat.2011.12.022
[47] Scharber MC, Mühlbacher D, Koppe M, Denk P, Waldauf C, Heeger AJ \& Brabec CJ, Advanced Materials 18 (2006) 789794. https://doi.org/10.1002/adma.200501717

[48] Luther J, Nast M, Fisch MN, Christoffers D, Pfisterer F, Meissner D, \& Nitsch J. Solar Technology. Ullmann's Encyclopedia of Industrial Chemistry, 2000. https://doi.org/10.1002/14356007.a24 369

[49] Shao S, Loi MA, Advance Material Interfaces, 7 (2020) 190146. https://doi.org/10.1002/admi.201901469

[50] Zhou D, Zhou T, Tian Y, Zhu X \& Tu Y, Journal of Nanomaterials, Article ID 8148072, (2018) 1-15 pages. https://doi.org/10.1155/2018/8148072

[51] Djuriši AB, Liu FZ, Tam HW, Wong MK, Ng A, Surya C, Chen W \& He Z B, Perovskite solar cells, Quantum Electron, 53 (2017) 1-37. https://doi.org/10.1016/j.pquantelec.2017.05.002

[52] Sharma S, Kumar P \& Chandra R, Journal of Composite Materials 51 (2016) 3299-3313. https://doi.org/10.1177/0021998316682363

[53] Balandin AA, Ghosh S, Bao W, Calizo I, Teweldebrhan D, Miao F, Lau C N, Nano Letters 8 (2008) 902-907. https://doi.org/10.1021/nl0731872

[54] Weiss N O, Zhou H, Liao L, Liu Y, Jiang S, Huang Y, Duan X, Advance Materials, 24 (2012) 5782-5825. https://doi.org/10.1002/adma.201201482

[55] Jiang J, Wang J, Li B, Physical Review B, 80 (2009) 113405. https://doi.org/10.1103/PhysRevB.80.134505

[56] Ding Z, Miao Z, Xie Z \& Liu J, Journal of Materials Chemistry A, 4 (2016) 2413-2418. https://doi.org/10.1039/C5TA10102F

DOI: https://doi.org/10.31875/2410-4701.2021.08.8

(C) 2021 Dhawan and Naqvi; Zeal Press.

This is an open access article licensed under the terms of the Creative Commons Attribution Non-Commercial License (http://creativecommons.org/licenses/by-nc/3.0/) which permits unrestricted, non-commercial use, distribution and reproduction in any medium, provided the work is properly cited. 